Martínez de Pisón Cavero, J. “Las personas LGBTIQ y sus derechos”, REDUR 19, diciembre 2021, págs. 57-70. ISSN 1695-078X. http://doi.org/10.18172/redur.5214

\title{
LAS PERSONAS LGBTIQ Y SUS DERECHOS
}

\author{
JOSÉ MARTÍNEZ DE PISÓN CAVERO1 \\ CATEDrático de Filosofía DEL DERECHO \\ UNIVERSIDAD DE LA RIOJA \\ jose.mezdepison@unirioja.es
}

SUMARIO: I. INTRODUCCIÓN. CONCEPTOS Y JUSTIFICACIÓN. II. SOBRE LA EXISTENCIA O NO DE UN DERECHO ESPECÍFICO PARA LAS PERSONAS LGBTIQ. III. ¿EXISTEN ELEMENTOS QUE PUEDAN PERMITIR LA CONSTRUCCIÓN Y JUSTIFICACIÓN DE UN DERECHO O DERECHOS PARA LAS PERSONAS LGBTIQ? IV. APUNTES PARA UNA MEJORA DE LA PROPOSICIÓN DE LEY DE IGUALDAD, RECONOCIMIENTO A LA IDENTIDAD SEXUAL Y/O EXPRESIÓN DE GÉNERO Y DERECHOS DE LAS PERSONAS TRANS Y SUS FAMILIARES EN LA COMUNIDAD AUTÓNOMA DE LA RIOJA. V. BIBLIOGRAFÍA.

RESUMEN. Durante los últimos años, el colectivo de personas LGBTIQ ha estado reivindicando un conjunto de derechos que refleje su realidad individual. Con este objetivo, los organismos internacionales, ONGs y activistas han elaborado documentos que han servido en la construcción de un "haz de derechos" para las personas LGBTIQ. En este proceso, ha sido muy relevante el activismo judicial, en particular, del Tribunal Europeo de Derechos Humanos de forma que se ha logrado el reconocimiento de un derecho a la orientación sexual, un derecho a la identidad de género y un derecho a la libre determinación del género.

PALABRAS CLAVE: personas LGBTIQ, derechos humanos, orientación sexual, identidad de género, libre determinación de género.

\section{LGBTIQ PEOPLE AND THEIR RIGHTS}

ABSTRACT. During the last years, the LGBTIQ people group has been claiming a set of rights that reflects their individual reality. With this objective, international organizations, NGOs and activists have produced documents that have served in the construction of a "bundle of rights" for LGBTIQ people. In this process, judicial activism has been very relevant, in particular, of the European Court of Human Rights in such a way

\footnotetext{
${ }^{1}$ Este trabajo ha sido realizado gracias a la ayuda REGI2020/49 grupos de investigación de la Universidad de La Rioja y del Banco de Santander.
} 
that the recognition of a right to sexual orientation, a right to gender identity and a right to freedom has been achieved. gender determination.

KEY WORDS: LGBTIQ people, human rights, sexual orientation, gender identity, gender self-determination.

\section{Introducción. Conceptos y justificación}

En la última década, han proliferado las mal llamadas "ley trans", esto es, leyes que recogen la opinión generalizada en la sociedad de que es necesario "despatologizar" la realidad de las personas trans al tiempo que recogen otras medidas anti discriminación del colectivo LGBTIQ. Una de las últimas Comunidades Autónomas en la que se está debatiendo y, previsiblemente, se aprobará en su Parlamento es la de La Rioja ${ }^{2}$. No es la primera, pues en España todas las CCAA, salvo tres, todas las demás ya han aprobado un tipo similar de normativa legal. Suelen ser conocidas como "leyes trans", pero, en realidad, extienden sus efectos a otros grupos del colectivo LGTBI, acrónimo habitualmente utilizado en nuestro país para referirse a las personas lesbianas, gays, trans, bisexuales e intersexuales

El uso de este acrónimo no es una cuestión pacífica. Allende nuestras fronteras, suele utilizarse el del LGBTI al que se añaden, de acuerdo a la singularidad de otros colectivos de minorías sexuales, otras mayúsculas o signos. Personalmente, creo que es más apropiado utilizar el de LGBTIQ tal y como aparece en la Union of Equality. LGBTIQ Equality Strategy 2020-2025, documento que concreta la estrategia por la igualdad, por la no discriminación y por los derechos de las personas de este colectivo por parte de la Comisión Europea para este período. Según la Estrategia, dada a conocer el 12 de noviembre de 2020, las personas LGBTIQ son aquellas personas que sienten atracción hacia otras de su propio género (lesbianas, gays) o de ambos (bisexual); aquellas cuya identidad y/o expresión de género no corresponde al sexo asignado en el momento del nacimiento (trans, nobinarios); aquellas que han nacido con características que no se ajustan a la definición típica de hombre o mujer (intersex); y aquellas cuya identidad no se ajusta a la clasificación binaria de la sexualidad y/o género (queer) $)^{3}$.

Con ello se pretende reflejar la variedad, diversidad y riqueza de este colectivo. Además, en mi opinión, a pesar de que los intereses y reivindicaciones, la historia y la lucha por los derechos ha sido diferente, sin embargo, es imprescindible una lectura inclusiva y englobadora de la realidad de las minorías sexuales que, dentro de la diversidad, respete las peculiaridades y dé respuesta a sus necesidades, evite la exclusión, la violencia y discriminación de estas personas.

\footnotetext{
${ }^{2}$ Estas páginas, salvadas algunas mínimas referencias, constituyen la parte central de mi intervención en la Comisión de Participación, Cooperación y Derechos Humanos del Parlamento de La Rioja del 18 de octubre de 2021. La intervención se centró en el análisis de la Proposición de Ley de igualdad, reconocimiento a la identidad sexual y/o expresión de género y derechos de las personas trans y sus familiares en la Comunidad Autónoma de La Rioja. Puede consultarse en https://www.parlamento-larioja.org/recursos-de-informacion/publicaciones-oficiales/boletinoficial/bopr-10-5a. Agradezco a Ana Santos Preciado y al grupo parlamentario socialista la oportunidad que me concedieron de exponer mis ideas y reflexiones sobre esta cuestión. Extiendo mi agradecimiento al resto de grupos y de parlamentarios de otros partidos políticos que tan atentamente escucharon mi intervención y mis sugerencias.

${ }^{3}$ Puede consultarse en https://ec.europa.eu/info/files/lgbtiq-equality-strategy-2020-2025_en, fecha consulta: $11 / 10 / 2021$.
} 
La perspectiva desde la que me acerco a la realidad del colectivo LGBTIQ es iusfilosófica; es, por tanto, desde la filosofía, desde los conceptos y los fundamentos, y desde el Derecho, desde la regulación jurídica, las declaraciones y los tratados y convenios internacionales. Mi intervención se ceñirá, así pues, a estos extremos. Desde esta perspectiva realizaré las siguientes explicaciones, así como alguna precisión. Para ello, recordaré algunas definiciones y, posteriormente, plantearé algunas preguntas con sus respuestas 4 .

Por orientación sexual, de acuerdo con los Principios de Yogyakarta (2006) se entiende "la vivencia de cada persona de sentir una profunda atracción emocional, afectiva y sexual por personas de un género diferente al suyo, o de su mismo género, o de más de un género, así como a la capacidad de mantener relaciones íntimas y sexuales con estas personas". Y por identidad de género "la vivencia interna e individual del género tal y como cada persona la siente profundamente, la cual podría corresponder o no con el sexo asignado al momento del nacimiento, incluyendo la vivencia personal del cuerpo (que podría involucrar la modificación de la apariencia o la función corporal a través de medios médicos, quirúrgicos o de otra índole, siempre que la misma sea libremente escogida) y otras

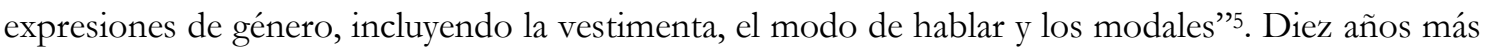
tarde, en los Principios de Yogyakarta+10, se precisaría la definición de expresión de género "como la presentación que cada uno hace de su género a través de la apariencia física -vestido, peinado, accesorios, cosméticos- gestos, habla, patrones de comportamiento, nombres y referencias personales, teniendo en cuenta que puede no ajustarse a la identidad de género de la persona" ${ }^{6}$.

De esta manera, con el concepto de orientación sexual se haría referencia a la realidad heterosexual y a la homosexual; con la identidad de género, al mundo trans; con la expresión de género, la realidad queer, cuir, no binaria, etc.

Ahora bien, las definiciones no siempre reflejan adecuadamente la realidad, los fenómenos que pretendemos describir y, en este caso, proteger a través del Derecho, si es que es factible. Esta afirmación es particularmente relevante en el caso de las personas trans. A veces no se tiene en cuenta que el colectivo trans es muy complejo y variado. Se tiende a pensar que son aquellas personas que quieren cambiar su aspecto a través de la cirugía, pero no es así. El concepto trans incluye a aquellas personas en las que no se produce una correspondencia entre sexo asignado en el nacimiento y el sexo sentido como el propio, como un elemento importante de la identidad personal. Por ello, suele entenderse que el término trans es de ámbito general e incluye diferentes grupos con sus perfiles y diversidad: hace referencia a transexuales, transgéneros y travestis. Los transexuales son aquellos trans que han optado por la modificación de su cuerpo a través de hormonación y la cirugía, es decir, por la reasignación del sexo; los transgéneros son quienes rechazan el cambio de sexo por medios médicos y lo hacen por diferentes razones, porque prefieren el sexo vivido, porque se niegan a escoger entre el género femenino o masculino, etc.; y el travesti, hace unas décadas muy utilizado en España, es la

\footnotetext{
${ }^{4}$ Quienes han estudiado las leyes de los Estados y de las CCAA de España desde una perspectiva de técnica jurídica señalan la diversidad de conceptos y de sus definiciones y las dificultades de comprensión. Por eso, en este texto se insiste en la necesidad de utilizar conceptos ya perfilados por organismos internacionales. Sobre los problemas de denominación de las leyes, así como del dispar empleo de términos puede verse P. de la CUESTA AGUADO, "Sexo, igualdad, diversidad y leyes LGTBI", Eunomía. Revista en Cultura de la Legalidad, 20, 2021, pp. 147 y ss.

${ }^{5}$ Vid. Principios de Yogyakarta: Principios sobre la aplicación de la legislación internacional de derechos bumanos en relación con la orientación sexual $y$ la identidad de género (https://www.refworld.org/cgibin $/$ texis $/$ vtx $/$ rwmain $/$ opendocpdf.pdf?reldoc $=y \& d o c i d=48244 \mathrm{e} 9 \mathrm{f} 2$, fecha de consulta 11/10/2021).

6 Vid. Principios Yogyakarta+10 (http://yogyakartaprinciples.org/wp-content/uploads/2017/11/A5_yogyakartaWEB2.pdf, fecha de consulta: 11/10/2021).
} 
persona que disfruta vistiéndose con ropa del sexo opuesto, y, en Latinoamérica, es sinónimo de transexual. A su vez, este grupo de personas pueden ser transexuales masculinos o transexuales femeninos, según si la reasignación del sexo ha sido a un género u otro ${ }^{7}$.

Aparentemente, en estas definiciones quedan fuera los intersexuales que aparecen como una minoría con sus particularidades, pero ajenos a los debates centrales. Adelanto que me parece muy positivo que la Proposición de Ley que estoy comentando recoja alguna regulación sobre la realidad intersex.

Pues bien, con este bagaje, podemos hacernos algunas preguntas básicas sobre los derechos del colectivo LGBTIQ:

1.- ¿Existe en los textos básicos sobre derechos humanos, especialmente en el plano internacional, un derecho o derechos que recoja y proteja los intereses, inquietudes y reivindicaciones de este colectivo? La respuesta es clara: No existe un derecho específico de las personas LGBTIQ. Más adelante, haré un comentario más extenso.

2.- ¿Existen elementos en el ámbito jurídico que, no obstante, permitan la construcción de un derecho o derechos específicos para este colectivo? La respuesta es, sin duda, Sí. Aunque es una cuestión que, incluso dentro del colectivo y del activismo no es pacífica.

3.- ¿Es pertinente, tanto a nivel internacional como nacional, la regulación de un derecho específico? Dicho de otra forma, ¿por qué parece necesario y exigible que se establezca uno o varios derechos, que el ordenamiento jurídico recoja y proteja los intereses del colectivo LGBTIQ en su diversidad? Porque son evidentes la homofobia, las conductas y actitudes de violencia, exclusión y discriminación hacia estas personas, porque debe garantizarse el respeto a su dignidad y libertad en condiciones de igualdad, porque, como seres humanos, tienen el mismo derecho que el resto de la sociedad a configurar su identidad, a moldear su personalidad y a planificar y desarrollar su vida en igualdad de condiciones con independencia de que su percepción de sexo o del género sea el de la mayoría de la sociedad.

No quiero extenderme en torno a la situación social, a nivel nacional o global, de las personas LGBTIQ que es, en realidad, el motivo último y justificación de la reivindicación de sus derechos, pues existen numerosos informes que la describen de forma muy cruda. Invito a quienes me escuchan a consultar, por ejemplo, el Informe Homofobia de Estado que, desde 2007 hasta la actualidad, elabora anualmente ILGA (International Lesbian, Gay, Bisexual, Trans and Intersex Association) donde se trata país a país tanto los casos y la situación del colectivo, como las legislaciones nacionales ${ }^{8}$. Esta labor tiene actualmente su proyección en la encomienda que el Consejo de Derecho Humanos ha realizado, primero, al Alto Comisionado de Naciones Unidas para los Derechos Humanos y, a partir de 2016, al Experto Independiente para que realicen los oportunos informes sobre la situación de estas personas. En el ámbito europeo, sigue teniendo una especial relevancia el Informe realizado por el Comisario de Derechos Humanos del Consejo de Europa, Th. Hammarberg, Derechos humanos e identidad de género (2009)9. Finalmente, en el ámbito de la Unión hay que recordar la Estrategia por la Igualdad 2020-2025 ya mencionada.

\footnotetext{
7 G. COLL-PLANAS, La voluntad y el deseo..., cit., p. 26 y vid. J. A. NIETO PIÑEROBA, Transexualidad, intersexualidad y dualidad de género, cit., p. 183.

${ }^{8}$ Vid en https://ilga.org/es

9 Th HAMMARBERG, Informe temático Derechos bumanos e identidad de género, Berlín, 2009, p. 15 (https://rm.coe.int/16806da528, fecha de consulta: 13/10/2021).
} 


\section{Sobre la existencia o no de un derecho específico para las personas LGBTIQ}

He afirmado antes que no existe en los textos internacionales sobre derechos humanos un derecho o derechos específicos que reconozca y proteja al colectivo LGBITQ. Pero, conviene hacer una importante matización. Cuando hablamos de "derechos humanos" en el derecho internacional hacemos referencia, principalmente, a tres textos muy importantes y que están en la mente de todos: la Declaración Universal de Derechos Humanos (DUDH), de 10 de diciembre de1948, y los Pactos Internacionales de Derechos Civiles y Políticos (PIDCP) y el Pacto Internacional de Derechos Económicos, Sociales y Culturales (PIDESC), aprobados en 1966. Estos textos pasaron en su día por un proceso de elaboración, discusión, firma y ratificación, especialmente los dos últimos. Conviene recordar que no se puede ser miembro de la ONU sin firmar y ratificar la Declaración Universal. Estos textos cumplieron los procedimientos y requisitos del derecho internacional para conllevar obligaciones para los Estados. En este sentido, los derechos fundamentales recogidos en estos textos podemos considerarlos como derechos humanos en el sentido fuerte: vinculan a los Estados y de ellos se derivan importantes obligaciones. Con todo, conviene recordar que el PIDESC tuvo un recorrido tortuoso y que hasta finales de los años 70 del siglo pasado no cumplió con los requisitos de ratificación para implicar obligaciones positivas para los Estados y que durante mucho tiempo los derechos económicos, sociales y culturales fueron considerados derechos de segunda categoría, susceptibles de incumplimiento. En los años 80 y 90, hubo un movimiento político global de reivindicación del carácter normativo y fuerte de estos derechos de manera que en la actualidad no hay declaración de Naciones Unidas sobre derechos humanos que no reitere la interdependencia de todos los derechos y su vinculatoriedad, es decir, que conllevaban obligaciones para los Estados.

Si ahora afrontamos la pregunta de, si desde el punto de vista estrictamente jurídico existen instrumentos en el derecho internacional que nos permitan fundamentar la existencia de un derecho a la libre determinación del género, está claro que la respuesta es NO. Y la consecuencia es que los poderes públicos no tienen la obligación de proteger, hacer respetar los derechos de estas personas, así como de favorecer su acceso al sistema sanitario público, a la educación, a un empleo digno, vivienda, etc. La regulación o no, la protección o no, la promoción o no de los derechos de estas personas queda relegada al ámbito interno; es una cuestión de política nacional en manos del gobierno de turno. Así la situación general del colectivo queda descrita crudamente en los informes antes mencionados. Sólo citar que, en el Informe Homofobia de Estado de 2020, ILGA constató que, de los 193 Estados estudiados, pertenecientes a Naciones Unidas, 70 penalizan de facto o de iure los actos sexuales consentidos entre personas adultas del mismo sexo. De ellos, 6 castigan esas relaciones con la pena de muerte a los que hay que añadir 5 más en los que potencialmente puede imponerse un castigo semejante ${ }^{10}$.

En esta situación, ¿cuál ha sido la estrategia de las personas LGBTIQ en la reivindicación de sus derechos o, mejor, en la necesaria restitución de los daños causados por otros (homofobia, agresiones, coacciones, encarcelamiento, discriminación en el acceso al sistema público de salud, en la la educación, en el mundo laboral, etc.). La estrategia ha sido utilizar una vía indirecta: acudir, primero, a los tribunales nacionales y después a los internacionales justificando sus pretensiones en el genérico principio de no discriminación apoyándolo, además, en otro de los derechos reconocidos

\footnotetext{
${ }^{10}$ Informe ILGA de Homofobia de Estado 2020, p. 27 (https://ilga.org/downloads/ILGA_Mundo_Homofobia _de_Estado_Actualizacion_Panorama_global_Legislacion_diciembre_2020.pdf, fecha de consulta 20/10/2021).
} 
en los textos constitucionales o en los aprobados en su momento a nivel regional o internacional: el derecho a la vida, el derecho a la integridad física y psíquica, el derecho a la vida privada o intimidad, el derecho al matrimonio, inviolabilidad del domicilio, etc. Esta ha sido una estrategia cuyo éxito no estaba garantizado, sobre todo en determinados ámbitos regionales ${ }^{11}$.

Especial relevancia tiene en esta lucha por los derechos y en su evolución el derecho a la vida privada, como explicaré a continuación. En definitiva, el fundamento último de los derechos de las personas LGBTIQ es el mismo que sustenta la universalidad de los derechos fundamentales de todos y hace referencia a las categorías jurídico-políticas más básicas de nuestra sociedad: nuestra concepción de la dignidad humana, de la libertad individual y de la igualdad y, en última instancia, el derecho al libre desarrollo de la personalidad.

\section{III. ¿Existen elementos que pueden permitir construir y justificar un derecho o derechos para las personas LGBTIQ?}

¿Es oportuno reivindicar y justificar un derecho o derechos específicos que proteja y asegure el disfrute de condiciones de libertad y no discriminación, de vida digna, a las personas LGBTIQ? En mi opinión, Sí. Y ello no debe extrañarnos en el contexto de la evolución de creación de los derechos fundamentales. Como pusieron de manifiesto Norberto Bobbio en Italia y Gregorio PecesBarba en España, desde hace décadas nos encontramos en la "fase de especificación de los derechos" en la cual se tiende a considerar a las personas en su situación concreta para atribuirle determinados derechos: como niño, como mujer, como tercera edad, como consumidor, etc. Habría que añadir como persona LGBTIQ.

Pues bien, a partir de esta premisa, puede afirmarse que se ha ido configurando, sobre todo, desde el inicio del siglo XXI, un "haz de derechos" que refleja la realidad y la concreta situación de las personas LGBTIQ: el derecho a la orientación sexual, el derecho a la identidad de género y el derecho a la libre determinación del género. Estos derechos se han ido construyendo paso a paso, progresivamente, e, incluso, en el caso del último, a falta de su reconocimiento constitucional, todavía se está pergeñando en las legislaciones nacionales, como son el caso de Argentina, Malta, Portugal, etc., y, en el caso de España, en la autonómica.

Hace un momento afirmé que no todo el colectivo está de acuerdo en que se materialicen sus reivindicaciones en uno o varios derechos específicos. En efecto, así es, pues un sector importante considera que, si los derechos humanos recogidos en la Declaración Universal de Derechos Humanos y en las constituciones nacionales, entre ellas, la española, son realmente universales, debería garantizarse la libertad y la igualdad a todas las personas y no debiera ser necesario ese nuevo derecho; bastaría con que los derechos fundamentales se aplicasen coherentemente a todos con independencia de su percepción del sexo y del género. A fin de cuenta el artículo 1 de la Declaración Universal de Derechos Humanos proclama que "todos los seres humanos nacen libres e iguales en dignidad y derechos, y que, dotados como están de razón y conciencia, deben comportarse fraternalmente los unos con los otros".

Fiel reflejo de esta posición es el documento Nacidos Libres e Iguales, elaborado por la Oficina del Alto Comisionado de Naciones Unidas (OACNUDH) y aprobado por el Consejo de Derechos Humanos de Naciones Unidas el 28 de septiembre de 2011 en el que se afirma que "la protección de

11 Vid. MONEREO ATIENZA, C., Diversidad de género, minorías sexuales y teorías feministas, Dykinson/Instituto Derechos Humanos Bartolomé de Las Casas Universidad Carlos III de Madrid, 2015, p. 60. 
las personas LGBT contra la violencia y la intimidación no exige la creación de una nueva serie de derechos específicos para ellas ni el establecimiento de nuevos estándares internacionales de derechos humanos", pues "las obligaciones que incumben a los Estados de proteger a las personas LGBT contra las violaciones de derechos humanos ya están establecidas y son vinculantes para todos los Estados miembros de las Naciones Unidas" ${ }^{12}$.

Sin embargo, en muchos Estados la realidad es muy otra. De ahí que, aunque quien les habla vea con simpatía esta posición, crea que es imprescindible desarrollar ese haz de derechos que procure protección en su disfrute a un colectivo tan vulnerable. Es más, a pesar de la ausencia de esa referencia en los textos básicos sobre derechos humanos, en mi opinión, existen mimbres para justificar el reconocimiento internacional y nacional de varios derechos específicos que darían cuerpo a ese haz de derechos.

Aunque sea brevemente, paso a relatar los elementos básicos que permiten fundamentar dichos derechos:

1.- La promoción por parte de activistas, ongs, académicos, organismos independientes de declaraciones favorables a estos derechos. Son numerosas. Cabe destacar la Declaración de Montreal (2006) entre otras. Pero, sin duda, la actuación más relevante fue la elaboración de los Principios de Yogyakarta: Principios sobre la aplicación de la legislación internacional en relación con la orientación sexual y la identidad de género, (2006), promovida por la Comisión Internacional de Juristas y el Servicio Internacional para los Derechos Humanos. Estos Principios fueron elaborados por 29 expertos independientes y, como explicita el subtítulo, fueron desgranando la legislación internacional de derechos humanos a la realidad de la orientación sexual e identidad de género incluyendo tanto el reconocimiento de derechos como la estipulación de obligaciones para los Estados. Además, estableció una serie de definiciones que han adquirido carta de naturaleza. El Consejo de Derechos Humanos de NU, en 2007, hizo suyos estos principios que así se han convertido en una referencia imprescindible en la defensa de los derechos de las minorías sexuales. Ante la ausencia de referencia a ciertos aspectos de la realidad trans, intersex y queer, estos 29 principios fueron ampliados en 2017 con otros diez, en los conocidos Principios de Yogyakarta+10, para así proceder al reconocimiento de un derecho a la libre determinación de género.

Otro documento importante es la Declaración Universal de Derechos Emergentes (DUDE) promovido también con una perspectiva más amplia por ongs, activistas de todo tipo, etc ${ }^{13}$.

2.- Una segunda vía ha sido la de promover iniciativas en el seno de Naciones Unidas que condujeran a un reconocimiento fuerte de los derechos de las minorías sexuales, sobre todo, en el seno de la Comisión de Derechos Humanos y en el Consejo de Derechos Humanos. Ha sido una importante lucha que ha generado no pocas resistencias. Uno de los hitos más importante se produjo en el año 2008 cuando 66 Estados presentaron a la Asamblea General una Declaración sobre derechos bumanos, orientación sexual e identidad de género, aprobada el 22 de diciembre de 2008, no sin polémica. Al día siguiente, 59 Estados presentaron otra declaración alegando que el derecho internacional de derechos

\footnotetext{
12 ACNUDH, Nacidos libres e iguales. Orientación sexual e identidad de género en las normas internacionales de derechos bumanos, New York/Ginebra, Oficina del Alto Comisionado Naciones Unidas para los Derechos Humanos, 2012, p. 9 (https://www.ohchr.org/Documents/Publications/BornFreeAndEqualLowRes_SP.pdf, fecha de consulta: 15/10/2021).

13 Declaración Universal de Derechos Humanos Emergentes, 2009, p.

(https://www.idhc.org/arxius/recerca/1416309302-DUDHE.pdf, fecha de consulta: 15/10/2021).

$58-59$
} 
humanos no contemplaba regulación sobre esta materia y que, en consecuencia, era competencia de cada estado.

Por su parte, el Consejo de Derechos Humanos, con sede en Ginebra, ha tenido una participación muy importante en la configuración de los derechos mencionados. Una resolución de 17 de junio de 2011 encarga al Alto Comisionado de Derechos Humanos la elaboración de informes sobre la práctica de los Estados en esta materia: sobre leyes, prácticas discriminatorias, actos de violencia, etc. La verdad es que sus estudios son muy importantes para conocer la realidad del mundo LGBTIQ. En 2016 se establece un Experto Independiente sobre la protección contra la violencia y la discriminación por motivo de orientación sexual o identidad de género.

3.- La tercera vía ha sido la de recurrir a la protección jurisdiccional para la protección y materialización de los derechos de las minorías sexuales. Ante la falta de un reconocimiento global de estos derechos y del establecimiento de mecanismos de protección, los colectivos LGBTIQ han recurrido, como anticipé, a tribunales internacionales de carácter regional para la protección de sus derechos. Con esta estrategia, la reivindicación de los derechos LGBTIQ ha ido sumando notables éxitos, especialmente, en relación con la actuación del Tribunal Europeo de Derechos Humanos (TEDH) hasta el punto de que puede afirmarse que la construcción de estos derechos es, sobre todo, jurisdiccional antes que legal. Es decir, que el TEDH es el que ha dado pasos de gigante en su configuración; de ahí, ha ido irradiando a otros ámbitos regionales y, por supuesto, ha influido en las naciones que componen el Consejo de Europa.

En el Convenio para la Protección de Derechos Humanos y de las Libertades Fundamentales (CEDH), como en los textos internacionales sobre derechos humanos de Naciones Unidas, no existe un derecho específico para el colectivo. Sin embargo, el TEDH, cuyo objetivo es asegurar el cumplimiento del CEDH, así como el de garantizar y proteger los derechos fundamentales en los países del Consejo de Europa, ha realizado una interpretación extensiva, flexible y abierta a los cambios de la sociedad europea que ha permitido la configuración vía jurisprudencial de un derecho a la orientación sexual. Para ello ha utilizado el art. 8 del Convenio que recoge el derecho a la vida privada. Así fue con la conocida sentencia Dudgeon vs Reino Unido, de 22 de octubre de 1981, por la que sentaba las bases del derecho a la orientación sexual y veinte años más tarde, con la sentencia Goodwin vs. Reino Unido, de 11 de julio de 2002, hacía lo propio con el derecho a la identidad de género.

Especialmente, nos interesa la segunda de las sentencias que es la que, de acuerdo con las definiciones adelantadas, recogería los derechos de las personas trans. No obstante, no quiero dejar pasar esta oportunidad de señalar que realmente han pasado más de 20 años desde el reconocimiento de un derecho a la orientación sexual, es decir, de un derecho que ampara la libertad e igualdad sexual de las personas homosexuales, hasta la determinación de un derecho a la identidad de género. Al mismo tiempo, conviene precisar que, ante la ausencia de un derecho semejante en los textos internacionales de derechos humanos o en las constituciones nacionales, estos derechos de las personas LGBTIQ son derechos de construcción jurisprudencial. Se van articulando y dotando de contenido caso a caso ligados a una interpretación extensiva y abierta del CEDH, sensible con los cambios de la sociedad europea, que realiza el TEDH.

En este sentido, el derecho a la identidad de género elaborado por el TEDH tiene también su fundamento en la interpretación del artículo 8 del CEDH en el que se regula el derecho a la vida privada. El TEDH, en su labor heurística, ha combinado esa interpretación extensiva del art. 8 CEDH junto a al convencimiento de la necesidad de limitar el poder de los estados para regular estos aspectos de la vida de las personas. El resultado es un derecho a la identidad de género cuyo contenido, en virtud de la inevitabilidad de los pronunciamientos caso a caso, tiene que ver con el cambio de nombre 
y la identidad sexual reflejada en documentos jurídicos oficiales, el derecho al matrimonio, a las relaciones paterno-filiales, la edad de jubilación y el derecho a la pensión. Es decir, de acuerdo a los asuntos sobre los que ha tenido que pronunciarse. En el caso Goodwin se encuentra la afirmación de que la negativa al cambio legal del nombre y de la identidad de género es "un grave atentado contra la vida privada, ya que un conflicto entre la realidad social y el Derecho coloca a la persona transexual en una situación anormal que le provoca sentimientos de vulnerabilidad, humillación y ansiedad" 14.

Como puede observarse, el contenido del derecho a la identidad de género tiene un efecto limitado en relación con la realidad de las personas trans, especialmente, cuando afecta al acceso al sistema público de salud, al objeto de realizar la reasignación de sexo, el derecho a la educación, a la vivienda o al mundo laboral. No obstante, poco a poco se va abriendo paso la idea, que ya aparece en esta primera sentencia, de que el respeto del derecho a la vida privada implica para los Estados tanto obligaciones negativas como positivas que ampararían estas últimas reivindicaciones de las personas trans.

El TEDH fue avanzando poco a poco del derecho a la identidad de género hacia un derecho de libre determinación, es decir, de un derecho más proactivo que implique acciones positivas para los Estados en el acceso al sistema público de salud en la reasignación del sexo, en el logro de condiciones igualitarias en el derecho a la educación y en el resto de derechos y libertades fundamentales. Y, por supuesto, en la liberación de las restricciones en el reconocimiento de la propia identidad, especialmente, la exigencia de informes médicos sobre su salud mental y de tratamientos hormonales.

Estas exigencias están en concordancia con las reivindicaciones de los movimientos sociales y con la lucha del activismo en contra de la patologización de la transexualidad. Movimientos cuyo origen se sitúa en torno a 2007 y que tomará cuerpo en la campaña STOP Trans Pathologization (2012) cuyo objetivo era "la retirada de la clasificación de los procesos de tránsito entre los géneros como trastorno mental de los manuales diagnósticos (DSM de la American Pyschiatric Association APA y CIE de la Organización Mundial de la Salud), el acceso a una atención sanitaria trans-específica públicamente cubierta, el cambio de modelo de atención sanitaria trans-específica, desde un modelo de evaluación a un enfoque de consentimiento informado, el reconocimiento legal de género sin requisitos médicos, la despatologización de la diversidad de género en la infancia, así como la protección contra la transfobia", según reza la web de este movimiento ${ }^{15}$. Conviene recordar que la transexualidad entró en 1980 en los manuales de diagnóstico mencionados como una enfermedad mental, con la denominación de "disforia de género", al tiempo que la homosexualidad dejaba de serlo. La despatologización, tras sucesivas campañas, se logró de hecho en 2018 con la supresión del CIE-11 de la transexualidad como enfermedad mental. Precisamente, las consecuencias de la despatologización es una de las cuestiones controvertidas dentro del mundo trans, pues de llevarse a cabo plenamente sacaría del sistema público de salud a los transexuales, es decir, a aquellos trans que están dispuestos a pasar por la cirugía para la reasignación del sexo. Dado que este tipo de intervenciones resultan caras, la gran mayoría sólo puede realizarla en el seno de la sanidad pública. Esta circunstancia lleva a que el movimiento reivindique que la despatologización no conduzca a esta situación y se siga teniendo derecho a la reasignación dentro del sistema público.

\footnotetext{
${ }^{14}$ La STEDH del caso Goodwin vs. Reino Unido puede verse en https://hudoc.echr.coe.int/spa?i=001-60596, fecha de consulta 10/10/2021.

15 Vid. web STP Stop Trans Pathologization (http://stp2012.info/old/es, fecha de consulta: 15/10/2021).
} 
Pues bien, en este proceso de elaboración de los derechos de las personas LGBTIQ -primero, el derecho a la orientación sexual, luego el derecho a la identidad de género-, puede afirmarse que el TEDH ha sentado las bases para un derecho a la libre determinación de género en sus diferentes denominaciones. Al año siguiente de la sentencia del caso Goodwin, en el proceso de I vs. Reino Unido (2003), el TEDH subraya que el fundamento del CEDH es la dignidad y la libertad de la persona y, en particular, la idea de que la autonomía personal es la piedra angular del concepto de vida privada y que esto implica que "la esfera personal de cada individuo está protegida, comprendiendo el derecho de cada uno a establecer los derechos de su identidad como ser humano". El TEDH reafirma el derecho de los transexuales, como todos los seres humanos, al derecho al desarrollo personal y a la integridad física y moral ${ }^{16}$.

Finalmente, en la sentencia Beizaras y Levickas vs. Lituania, de 14 de enero de 2020, ha dado un importante paso hacia el reconocimiento del derecho a la libre determinación de género al afirmar: que una de las "señas de identidad de una sociedad democrática" es el respeto del pluralismo, la tolerancia y la amplitud de miras, que la misma se construye "en el reconocimiento genuino y el respeto de la diversidad", que el concepto de "vida privada" es un término amplio susceptible de abarcar la integridad física y psicológica de una persona y que la autodeterminación sexual "constituye uno de los aspectos del derecho de una persona al respeto de su vida privada" ${ }^{17}$.

4.- Por tanto, la construcción de los derechos LGBTIQ ha sido, en buena medida, una labor jurisprudencial, pero, en cuarto lugar, ante su ausencia en los textos internacionales y en las constituciones nacionales, en los últimos años está siendo muy importante el papel de los legisladores tanto en el plano estatal como en el regional o autonómico. En efecto, la vía de reconocimiento y protección de los derechos de las minorías sexuales se está realizando en la última década a través de la acción positiva del legislador, especialmente, destinada a la configuración legal de un derecho a la libre autodeterminación. Destacan en estas actuaciones países, en la UE, Malta, Portugal, Bélgica, Dinamarca, Irlanda y Luxemburgo; en el resto de Europa, Noruega, Islandia y Suiza; y en Latinoamérica, Argentina, Bolivia, Brasil, Chile, Colombia, Ecuador, México, Panamá, Perú y Uruguay. Fuera de estas zonas, también se recoge en países como Australia.

Argentina fue pionera en el reconocimiento de un "derecho a la identidad de género" con un contenido más amplio del que había definido el TEDH. Lo hizo con la Ley 26.743, de 23 de mayo de 2012, una ley pensada para dar respuesta a las reclamaciones del mundo trans, aunque también del intersex, puesto que se regula la reasignación de sexo, el cambio de identidad, el acceso al sistema de salud, la no discriminación, la situación de los menores trans, etc.

En la Unión Europea, Malta ha adquirido un protagonismo especial, pues fue el primer país que prohibió la cirugía de sexo o los tratamientos médicos o psicológicos como requisito previo a la reasignación o el cambio de identidad. De nuevo, esta prohibición tiene repercusiones tanto para el mundo trans como el intersexual. El art. 3 de la Ley sobre identidad de género, expresión de género y características sexuales, de 14 de abril de 2015, afirma que sus ciudadanos tienen derecho al reconocimiento a la identidad de género; al libre desarrollo de su personalidad de acuerdo con su identidad de género; a ser tratado de acuerdo a su identidad de género y, particularmente, a ser

\footnotetext{
${ }^{16} \mathrm{La}$ SETDH del caso I vs. Reino Unido puede verse en https://hudoc.echr.coe.int/spa?i=001-60595, fecha de consulta el 12/10/2021.

17 Caso Beizaras y Levickas vs. Lituania, de 14 de enero de 2020, parágrafos 106-110, vid. https://insignis.aranzadidigital.es/maf/app/document?srguid=i0ad6adc50000017e5296e9a502b71a20, última consulta el 16/10/2021.
} 
identificado de esa manera en los documentos de identidad; y a la integridad corporal y autonomía física.

Portugal aprobó la ley 38/2018, de 7 de agosto, sobre el Derecho a la autodeterminación de la identidad de género y expresión de género y la protección de las características sexuales de las personas, cuyo contenido se regula en el artículo 1. Según el texto legal, el fundamento de este derecho a la autodeterminación de la identidad de género y la expresión de género reside en el libre desenvolvimiento de la personalidad de acuerdo con la identidad y la expresión de género de cada cual. Se reconoce el derecho a mantener las características sexuales primarias y secundarias, se prohíben las intervenciones quirúrgicas o tratamientos farmacológicos en los menores intersexuales salvo riesgo para la salud, se prohíbe la discriminación, el derecho al cambio de nombre con un procedimiento rápido y se incluyen medidas de protección de las personas trans e intersexuales en el ámbito de la salud y de la educación.

Y, en España, ¿cómo está la situación? Por un lado, hay que anotar la iniciativa del grupo parlamentario confederal Unidos Podemos-En Comú Podem-En Marea al presentar una Proposición de Ley sobre la protección jurídica de las personas trans y el derecho a la libre determinación de la identidad sexual y expresión de género, publicada en el Boletín Oficial de las Cortes Generales el 2 de marzo de 2018. El art. 2.1 establecía que "toda persona es titular del derecho a la libre determinación de la identidad sexual y expresión de género". En la Proposición de Ley se desarrollaba este derecho, su ejercicio, así como el derecho a la adecuación de los datos personales, los derechos en el ámbito sanitario y de la salud, en el ámbito social y laboral, en la educación. Como es sabido, decayó la legislatura sin que la ley pudiera aprobarse.

Más recientemente, parece sustanciarse otra iniciativa de ley de la que se conoce algún borrador. Más en concreto, de la Ley para la igualdad real y efectiva de las personas trans. El art. 1 especifica que el objeto de la ley es "promover y garantizar la igualdad real y efectiva de las personas trans, mediante el reconocimiento del derecho a la identidad de género libremente manifestada, como exigencia de la dignidad humana y requisito para el libre desarrollo de la personalidad". Sin duda, es un gran avance en la reafirmación de los derechos de las personas trans y del colectivo LGBTIQ: despatologiza la realidad trans, suprime los requisitos médicos para el cambio de identidad de género, contempla también la difícil situación de los menores; se prevén medidas en los diferentes ámbitos en los que estas personas han sufrido discriminación y exclusión, como la salud, la educación, el empleo, incluso, las cárceles. Veremos qué sucede en el futuro dada la polémica que ha generado.

En este contexto, en el que las Cortes Generales no han aprobado una ley que refleje la realidad de las personas LGBTIQ han sido las CCAA las que han tomado la iniciativa. Desde 2009, 12 CCAA han regulado total o parcialmente la situación del colectivo LGBTIQ, en particular, de las personas trans, prohibiendo su patologización y protegiendo sus derechos. De ellas, 8 reconocen o hacen alusión al "derecho a la autodeterminación de género". La primera que lo incluyó fue la ley andaluza en su Ley integral para la no discriminación por motivos de género y reconocimiento de los derechos de las personas transexuales, de 8 de julio de 2014. En la misma línea la ley valenciana, Ley 8/2017, de 7 de abril, de la Generalitat, integral del reconocimiento del derecho a la identidad y a la expresión de género.

\section{Apuntes para una mejora de la Proposición de Ley de igualdad, reconocimiento a la identidad sexual y/o expresión de género y derechos de las personas trans y sus familiares en la Comunidad Autónoma de La Rioja}

De las 3 CCAA que no ha regulado los derechos de las personas LGBITQ y, en particular, del colectivo trans, una de ellas es La Rioja. Por eso, quiero, ante todo, felicitar a sus Señorías y, en 
general, a todos los parlamentarios por llevar a cabo esta iniciativa de presentar, elaborar y aprobar, en su caso, la Proposición de Ley de igualdad, reconocimiento a la identidad sexual y/ o expresión de género y derechos de las personas transy sus familiares en la Comunidad Autónoma de La Rioja. Mis últimas palabras en esta comparecencia van a dirigidas a realizar un breve comentario sobre esta Proposición de Ley.

Mi especialidad no es la técnica legislativa. De ahí que el final de la intervención sean unas someras palabras sobre el texto. Reitero mi satisfacción y la de muchos riojanos que van a ver regulada una situación muy especial, en la que muchas veces hay incomprensión y sufrimiento. Me parece muy meritorio el art. 2 del texto en el que se especifica el contenido del derecho a la autodeterminación de género: especialmente, su apartado 2 en el que se especifica que toda persona tiene derecho "al reconocimiento de su identidad de género, libremente determinada, y a ser tratada con pleno respeto y sin menoscabo de su dignidad y libertad". Esta Proposición de Ley extiende, en el marco de competencias de la CA, a diferentes ámbitos de la vida social: sanidad, educación, laboral, social, comunitario. Merecer la pena resaltar el hecho de que alguno de sus efectos se proyecte tanto a los transexuales como a los intersexuales (art. 18) y que estén expresamente prohibidas en la CA de La Rioja las terapias de conversión (art. 13.4). Sin duda, es un importante avance en la protección de los derechos de un sector relevante del colectivo LGBTIQ.

Tan solo quiero apuntar dos aspectos que quizá pudieran modificarse:

1.- El primero es en el ámbito educativo. La Proposición de Ley, en su art. 10.3, hace referencia a los centros educativos públicos, concertados y privados. En el art. 11, a la Universidad de La Rioja, único centro público de educación superior. El texto parece olvidar que también hay un centro universitario privado que, quizás, debería verse afectado por el contenido de la futura Ley.

2.- Por último, una referencia a los menores trans y su identidad de género. La Ley 3/2007 de 15 de marzo reguladora de la Rectificación Registral de la Mención relativa al Sexo de las Personas, en sus art. 1 y 4 , establece que las personas mayores de edad podrán proceder a la rectificación registral de la mención del sexo siempre que se acredite disforia de género y que haya sido tratado "médicamente durante al menos dos años para acomodar sus características físicas a las correspondientes al sexo reclamado". Esta regulación, a pesar de ser un avance respecto a la situación anterior, fue criticada, primero, por mantener la tesis de la patologización de las personas trans y, además, por impedir la rectificación a los menores de edad. El Tribunal Constitucional, en su sentencia 9/2019, de 18 de julio, declaró inconstitucional el requisito de la mayoría de edad bastando, para proceder al cambio de sexo y de nombre de los menores, con probar "suficiente madurez y que se encuentren en una situación estable de transexualidad".

El borrador de la Ley para la igualdad real y efectiva de las personas trans establece un nuevo criterio de edad: las personas trans mayores de 16 años estarán legitimadas para solicitar la rectificación registral; los menores entre 12 y 16 años podrán hacerlo a través de sus representantes legales o por sí mismos con su consentimiento; y, en el caso de los menores de 12 años, serán los representantes legales con su conformidad los que podrán solicitar la rectificación registral. En caso de conflicto entre los representantes legales y el menor se prevé el nombramiento de un "defensor judicial" de conformidad con el art. 300 del Código civil.

Mi sugerencia es que, quizás, no se debería dejar pasar la oportunidad de adaptar alguno de los preceptos de la Proposición de Ley a estos previsibles cambios normativos, especialmente, aquellos que regulan la atención sanitaria. En concreto, el art. 15 en el último párrafo de la letra b), su apartado 3 y su apartado 4. En particular, este último apartado en el que se especifica que el menor trans que supere los 12 años sólo será "oído en atención a su desarrollo y madurez" en el inicio de los 
tratamientos hormonales. Si bien, sin duda, esta regulación puede ser discutible, no parece que sea razonable que la Proposición de Ley establezca que las personas trans que superen los 16 años tan sólo tendrán derecho a que se recabe su consentimiento "de manera clara e inequívoca" puesto que parece chocar con la tesis del borrador de ley estatal que, a efectos de la rectificación registral, la edad a partir de la que se tiene plena legitimidad son los 16 años.

\section{Bibliografía}

AA.VV., Orientació sexual $i$ identitat de gènere. Els drets menys entesos, Institut de. Drets Humans de Catalunya, Barcelona, 2007 (https://www.idhc.org/arxius/recerca/1533629180-CDHE_03.pdf)

ÁLVAREZ RODRÍGUEZ, I., "La organización de Naciones Unidas y los derechos de las personas LGTBI: nuevos avances y desafíos de siempre" en F. J. Matia Portilla, A. Elvira Perales y A. Arroyo Gil, Laprotección de los derechos fundamentales de personas LGTBI, Tirant lo Blanch, Valencia, 2019, pp. 23-65.

BUSTOS MORENO, Y. B., La transexualidad (de acuerdo a la Ley 3/2007, de 15 de maræo), Dykinson, Madrid, 2008.

COLL-PLANAS, G., La voluntad y el deseo. La construcción social del género y la sexualidad: el caso de lesbianas, gay $y$ trans, $2^{a}$ ed., Egales, Barcelona, 2011.

COLL-PLANAS G. y VIDAL, M., Dibujando el género, 2ª ed., Egales, Barcelona, 2013.

CUESTA AGUADO, P. de la, “Sexo, igualdad, diversidad y leyes LGTBI”, Eunomía. Revista en Cultura de la Legalidad, 20, 2021, pp. 141-154.

GARIAZABAL, C., “Transexualidades, identidades y feminismos”, en M. Missé y G. Coll-Planas, El género desordenado. Críticas en torno a la patologización de la transexualidad, prol. de J. Butler, $3^{\mathrm{a}}$ edic., Egales, Barcelona, 2010, p. 125-140.

HAMMARBERG, TH., Informe temático Derechos bumanos e identidad de género, Berlín, 2009, (https://rm.coe.int/16806da528).

HERNÁNDEZ GONZÁLEZ, M., RODRÍGUEZ MORALES G. y GARCÍA-VALDECASAS CAMPELO, J., "Género y sexualidad: consideraciones contemporáneas a partir de una reflexión en torno a la transexualidad y los estados intersexuales", Revista de la Asociación Española de Neuropsiquiatría, vol. 30, nº 105, enero-marzo 2010, pp. 75-91.

MARTÍNEZ DE PISÓN, J., "Los derechos de las personas LGBTI: ¿hacia un derecho a la orientación sexual y la identidad de género", Cuadernos Electrónicos de Filosofía del Derecho, 42, 2020, pp. 209-239.

MARTÍNEZ DE PISÓN, J., "Sexo, género y derechos: del 'derecho a la orientación sexual y la identidad de género' al 'derecho a la libre determinación de género", Derechosy Libertades, enero de 2022, (aprobado para su publicación).

MARTÍNEZ DE PISÓN, J., "La identidad de género en el Tribunal Europeo de Derechos Humanos", Anuario de Filosofía del Derecho, 2022, (aprobado para su publicación).

MATIA PORTILLA, F. J., ELVIRA PERALES, A. y ARROYO GIL, A., La protección de los derechos fundamentales de personas LGTBI, Tirant lo Blanch, Valencia, 2019. 
MISSÉ, M. y COLL-PLANAS, G., El género desordenado. Críticas en torno a la patologización de la transexualidad, prol. de J. Butler, $3^{a}$ ed., Egales, Barcelona, 2016.

MONEREO ATIENZA, C., Diversidad de género, minorías sexuales y teorías feministas, Dykinson/Instituto Derechos Humanos Bartolomé de Las Casas, Universidad Carlos III de Madrid, Madrid, 2015.

NIETO PIÑEROBA, J.A., Transexualidad, intersexualidad y dualidad de género, Ediciones Bellaterra, Barcelona, 2008.

PEÑA DÍAZ, F. de A., La lucha que no cesa. Los derechos del colectivo LGBTI como derechos humanos, Tirant lo Blanch, Valencia, 2018.

PÉREZ SEDEÑO, E. y ORTEGA ARJONILLA, E., eds., Cartografias del cuerpo. Biopolíticas de la ciencia y la tecnología, Cátedra/Universidad de Valencia, Madrid, 2014.

SOLEY-BELTRÁN, P., Transexualidady la matriz heterosexual. Un estudio crítico de Judith Butler, Ediciones Bellaterra, Barcelona, 2009. 